Polymer Journal, Vol. 39, No. 2, pp. 163-174 (2007)

(C)2006 The Society of Polymer Science, Japan

\title{
Microstructural Characterisation and Properties Evaluation of Poly (methyl methacrylate-co-ester)s
}

\author{
Seema AgARWAL ${ }^{\dagger}$ \\ Philipps-Universität Marburg, Fachbereich Chemie, Hans-Meerwein Strasse, D-35032, Marburg, Germany
}

(Received October 20, 2006; Accepted November 9, 2006; Published December 21, 2006)

\begin{abstract}
The present work provides detailed copolymerization behavior of methyl methacrylate (MMA) with 2-methylene-1,3-dioxepane (MDP), a cyclic ketene acetal under conventional free radical polymerization conditions at $120^{\circ} \mathrm{C}$. An in-sight to the microstructure of the homo- and co-polymers is also made available using 1D and 2D NMR spectroscopic techniques. For the first time we showed the formation of crystalline degradable aliphatic polyester, homo poly (2-methylene-1,3-dioxepane) (PMDP) with reduced branches using radical-ring-opening-polymerisation. The copolymerization brought degradability and many other new properties to the poly (methyl methacrylate) (PMMA) vinyl polymer. Various degradable materials based on MMA and 2-methylene-1,3-dioxepane (poly (MMA-co-ester)s) containing varied amounts of ester linkages ranging from amorphous to crystalline and with different glass transition temperatures are generated. The presence of very low fraction of the ester linkages (about $10 \mathrm{~mol} \%$ ) could led to a significant increase in the thermal stability of PMMA. These materials are shown to have heat-shrinkable-shape-memory properties also. [doi:10.1295/polymj.PJ2006137]

KEY WORDS Degradable Vinyl Polymers / Poly (methyl methacrylate) / Cyclic Ketene Acetals / Microstructure / Thermal Properties / Heat-Shrinkable /
\end{abstract}

Originally polymers were synthesised because of their excellent physical and chemical stability providing durability. But in recent times the resistance of conventional synthetic polymers with $\mathrm{C}-\mathrm{C}$ backbones like polyolefins, polystyrene (PS), poly (methyl methacrylate) (PMMA) etc. to the degrading action of different agencies like living system, chemicals or light is considered as a problem in several domains where they are used for a limited period of time. One of the methods of engineering degradability into these non-degradable vinyl polymer backbones is by the addition of one of the unstable chemical linkages like esters.

First, Bailey and co-workers and later some others studied the free radical ring-opening homo polymerization (RROP) of different cyclic ketene acetal monomers like 2-methylene-1,3-dioxepane (MDP), 2-methylene-4-phenyl-1,3-dioxalane (MPD) and 5,6-benzo2-methylene-1,3-dioxepane (BMDO) using conventional radical initiators like azobisisobutyronitrile (AIBN) and $t$-butyl peroxide (TBPO), photoinitiators and controlled radical polymerisations generating polyesters. ${ }^{1}$ The use of these monomers with exo methylene group in radical initiated copolymerisation with vinyl monomers could introduce degradable polar linkages like ester linkages onto the hydrocarbon backbone of vinyl polymers (Scheme 1).

Previously we have reported for the first time the detailed copolymerization behaviour of cyclic ketene acetal BMDO with vinyl monomers like styrene (St) and methyl methacrylate (MMA) under ATRP reaction conditions with an aim to generate degradable vinyl polymers. ${ }^{2}$ Detailed 2D NMR characterization of the copolymers showed exclusively (100\%) ring opening polymerization (ROP) reaction of BMDO during copolymerization. Later, we showed the formation of new degradable poly (pentafluorostyreneco-ester)s using conventional radical initiators and their utility in making superhydrophobic surfaces using electrospinning technique. ${ }^{3}$

2-Methylene-1,3-dioxepane (MDP) is an interesting cyclic ketene acetal monomer giving poly ( $\varepsilon$-caprolactone) (PCL), a well studied and in-demand degradable aliphatic polyester, on the radical-ring-opening homopolymerisation and can introduce ester groups onto the vinyl polymer backbones during copolymerisations with vinyl monomers. First, it's copolymerisation capability with some vinyl monomers like MMA, vinyl anisole, vinyl acetate and styrene is reported by Bailey et al. without mentioning in details about the copolymer structure and properties of the resulting materials. ${ }^{4}$ Only mention in their work is the reactivity ratios of 0.021 and 22.6 for MDP and styrene respectively for copolymerisation of MDP and styrene. ${ }^{4}$ Later, complete absence of copolymerisation and formation of only homo polystyrene was shown by Davis et al. for the same system, i.e., MDP and styrene copolymerisation. ${ }^{5}$ In general, due to the low reactivity of the cyclic ketene acetals, their copolymerisation with vinyl monomers and the random introduction

${ }^{\dagger}$ To whom correspondence should be addressed (E-mail: Seema@chemie.uni-marburg.de). 


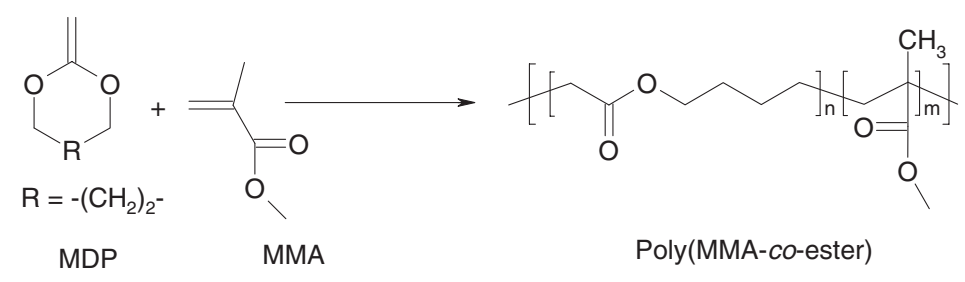

Scheme 1. Copolymerisation of cyclic ketene acetals with vinyl monomers (copolymerisation of MDP and MMA as specific example).

of ester linkages is difficult.

Keeping in view our broad aim of synthesising high molecular weight new degradable materials with new properties based on the conventional plastics, here an attempt has been made to study the copolymerisation behaviour of MMA and MDP under conventional radical polymerisation conditions. The microstructrure of the materials plays a crucial role in deciding the ultimate properties. A study for microstructural characterisation of the homo- and copolymers is reported for the first time using $1 \mathrm{D}$ and 2D NMR techniques. To the best of our knowledge, thermal and smart heat shrinkable properties of the copolymers are also reported for the first time.

\section{EXPERIMENTAL}

\section{Materials}

MDP (Polysciences, Inc.) and TBPO (Aldrich) were used as received. Methyl methacrylate (MMA) (Aldrich) was dried over $\mathrm{CaH}_{2}$ and distilled before use. $\mathrm{MeOH}$ and THF were distilled before use.

\section{Radical Copolymerisation of MMA and MDP}

In general, all copolymerisation reactions were carried out under argon in predried Schlenk tubes. In a typical copolymerisation reaction (run 4, Table I), $0.57 \mathrm{~g}\left(5 \times 10^{-3}\right.$ moles $)$ of MDP, $0.50 \mathrm{~g}\left(5 \times 10^{-3}\right.$ moles) of MMA and $1 \mathrm{wt} \%$ of the total monomers of $t$-butyl peroxide (TBPO) were placed in an schlenk tube under argon. The mixture was degassed by one cycle of freeze-pump-thaw and then placed in a pre-

Table I. Copolymerisation of MMA and MDP using $1 \mathrm{wt} \%$ TBPO initiator $\left(\mathrm{Temp} .=120^{\circ} \mathrm{C}\right.$; time $=2 \mathrm{~h}$ )

\begin{tabular}{|c|c|c|c|c|c|c|c|}
\hline \multirow[t]{2}{*}{ S.No. } & \multicolumn{2}{|c|}{$\begin{array}{l}\text { Feed composition } \\
\text { (molar ratio) }\end{array}$} & \multicolumn{2}{|c|}{$\begin{array}{c}\text { Copolymer } \\
\text { composition } \\
\text { (molar ratio) }\end{array}$} & \multirow[t]{2}{*}{$\begin{array}{c}\text { Yield } \\
(\%)\end{array}$} & \multirow[t]{2}{*}{$M_{\mathrm{n}} \times 10^{-4}$} & \multirow[t]{2}{*}{$M_{\mathrm{w}} / M_{\mathrm{n}}$} \\
\hline & MDP & MMA & MDP & MMA & & & \\
\hline 1 & 15 & 85 & 10 & 90 & 70 & 18.9 & 2.1 \\
\hline 2 & 26 & 74 & 16 & 84 & 66 & 20.0 & 2.2 \\
\hline 3 & 38 & 62 & 22 & 78 & 61 & 16.0 & 2.4 \\
\hline 4 & 50 & 50 & 30 & 70 & 59 & 12.2 & 2.0 \\
\hline 5 & 64 & 36 & 44 & 56 & 54 & 7.5 & 2.4 \\
\hline 6 & 78 & 22 & 57 & 43 & 40 & 5.5 & 2.6 \\
\hline
\end{tabular}

heated oil bath at $120^{\circ} \mathrm{C}$. After desired interval of reaction time, the reaction mixture was diluted with THF and precipitated in about $200 \mathrm{~mL}$ methanol. Purification of the polymers was done by dissolving in THF and reprecipitation in methanol. The drying of the copolymers was done in vacuum at $30^{\circ} \mathrm{C}$ until constant weight. The homo- and different copolymers of MDP and MMA were made by changing the molar ratio of the two monomers in the feed, under similar reaction conditions as described above. Details of the reaction conditions with monomer feed ratios are given in the Table I.

\section{Hydrolysis of MDP-MMA Copolymers}

$250 \mathrm{mg}$ of the copolymer samples were stirred in $30 \mathrm{~mL}$ of $\mathrm{KOH}$ in methanol $(5 \mathrm{wt} \%)$ for $8 \mathrm{~h}$. After this $5 \mathrm{~mL}$ of concentrated hydrochloric acid was added. The solution was extracted with chloroform, dried over sodiumsulfate, and the material left after evaporation of the solvent was further characterised.

\section{Characterization}

Molecular weight of the polymers were determined by GPC using Knauer system equipped with 2 columns PSS-SDV (linear, $10 \mu \mathrm{L}, 60 \times 0.8$ ), a differential refractive index detector and a UV photometer using THF as eluent at a flow rate of $0.83 \mathrm{~mL} / \mathrm{min}$.

${ }^{1} \mathrm{H}(400.13 \mathrm{MHz})$ and ${ }^{13} \mathrm{C}(100.21 \mathrm{MHz})$, NMR spectra were recorded on a Bruker DRX-400 spectrometer. Tetramethylsilane (TMS) was used as internal standard. ${ }^{1} \mathrm{H}^{13} \mathrm{C}$ correlation experiments were performed on a Bruker DRX-500 spectrometer, with a $5 \mathrm{~mm}$ multinuclear gradient probe and using gsHMQC and gs-HMBC pulse sequences. The HMQC experiment was optimized for $\mathrm{C}-\mathrm{H}$ coupling of 140 $\mathrm{Hz}$, with decoupling applied during acquisition; while the HMBC experiment was optimized for coupling of $8 \mathrm{~Hz}$, with decoupling during acquisition. 2D NMR data were acquired with 2048 points in $t_{2}$, and the number of increments for $t_{1}$ was 256. 4 and 8 scans were used for HMQC and HMBC experiments respectively, and dummy scans of 4 was used for both the experiments. A relaxation delay of $1 \mathrm{~s}$ was used for all $1 \mathrm{D}$ experiments and $2 \mathrm{~s}$ for all $2 \mathrm{D}$ experiments. Typical experiment time was about $1.5 \mathrm{~h}$ and $3.0 \mathrm{~h}$ for HMQC and HMBC respectively. 

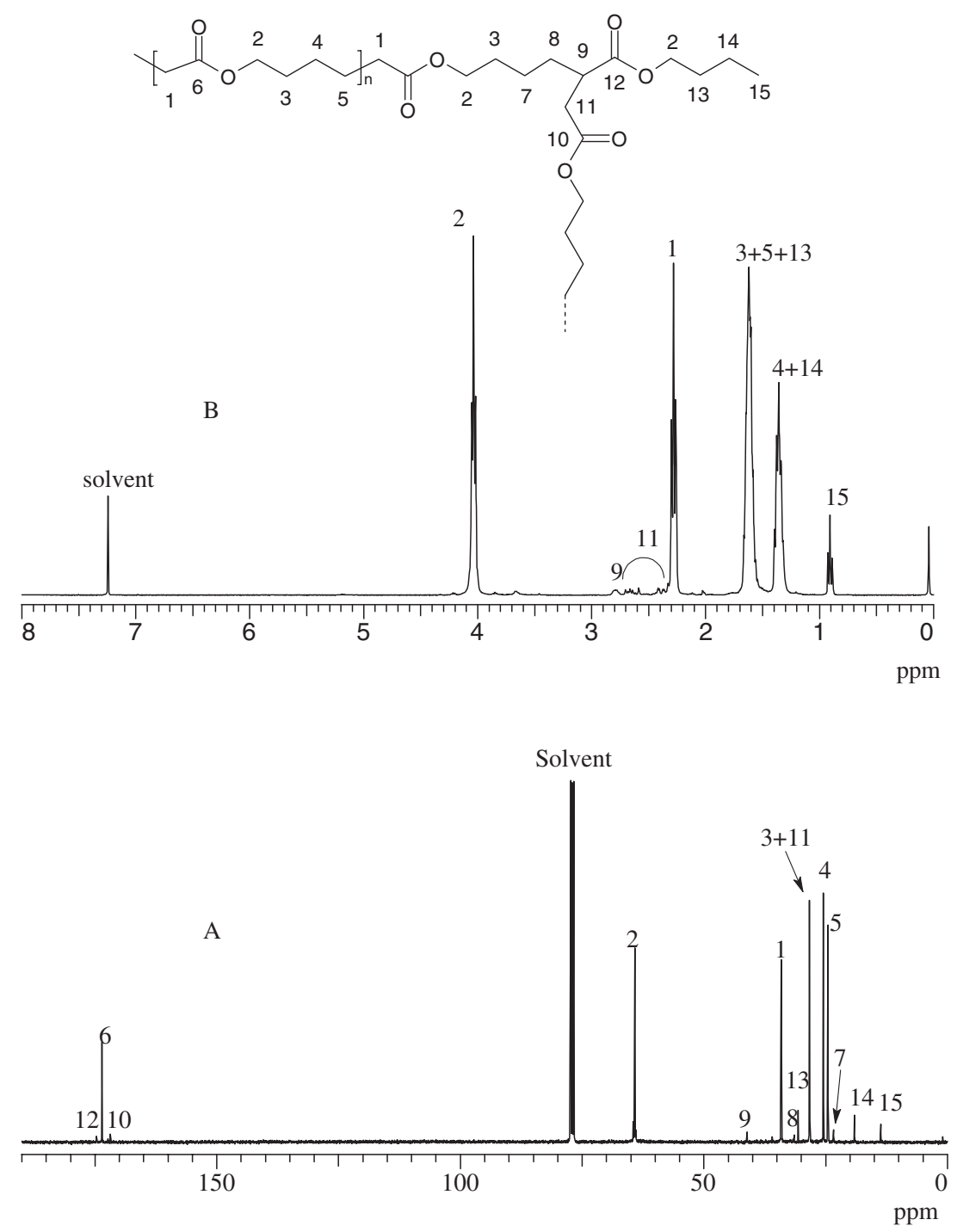

Figure 1. NMR spectra of PMDP made at $120{ }^{\circ} \mathrm{C}$ by radical ring-opening polymerisation A) ${ }^{13} \mathrm{C}$ NMR; B) ${ }^{1} \mathrm{H}$ NMR.

Mettler thermal analysers having $851 \mathrm{TG}$ and 821 DSC modules were used for the thermal characterization of copolymers. DSC scans were recorded in nitrogen atmosphere at a heating rate of $10^{\circ} \mathrm{C} / \mathrm{min}$. Thermal stability was determined by recording TG traces in nitrogen atmosphere (flow rate $=50 \mathrm{~mL} / \mathrm{min}$ ) using powdered samples. A heating rate of $10^{\circ} \mathrm{C} / \mathrm{min}$ and sample size of $10 \pm 1 \mathrm{mg}$ was used in each experiment.

\section{RESULTS AND DICUSSION}

The detailed studies regarding the copolymerization behavior and properties evaluation of MDP and MMA are required in order to recommend the new materials poly (MMA-co-ester)s for different applications. In the present study, homo- and copolymerisation of MDP and MMA was carried out under conventional free radical polymerization reaction conditions (Scheme 1). $t$-Butyl peroxide (TBPO) was used as an initiator at $120^{\circ} \mathrm{C}$. Our previous experience with radical ring-opening-polymerisation with other vinyl monomers made us to use higher temperature $\left(120^{\circ} \mathrm{C}\right)$ for polymerizations. The various copolymers of MDP with MMA were made by changing the molar ratio of the two monomers in the initial feed (Table I).

The structural characterization of the homopolymers and copolymers was done in $\mathrm{CDCl}_{3}$ using various NMR spectroscopic techniques. The representative ${ }^{1} \mathrm{H}$ and ${ }^{13} \mathrm{C}$ NMR spectra of the homopolymer poly (2-methylene-1,3-dioxepane) (PMDP) is shown in the Figure 1.

The RROP of MDP is expected to generate degradable linear aliphatic polyester poly( $\varepsilon$-caprolactone) (PCL). The peaks obtained from the polyester repeat unit after ring-opening polymerization of MDP under our experimental conditions are marked by comparing it with that of pure poly ( $\varepsilon$-caprolactone) ${ }^{6}$ Both ${ }^{1} \mathrm{H}$ and ${ }^{13} \mathrm{C}$ NMR spectra showed some extra peaks in comparison to the pure PCL there by showing a devi- 

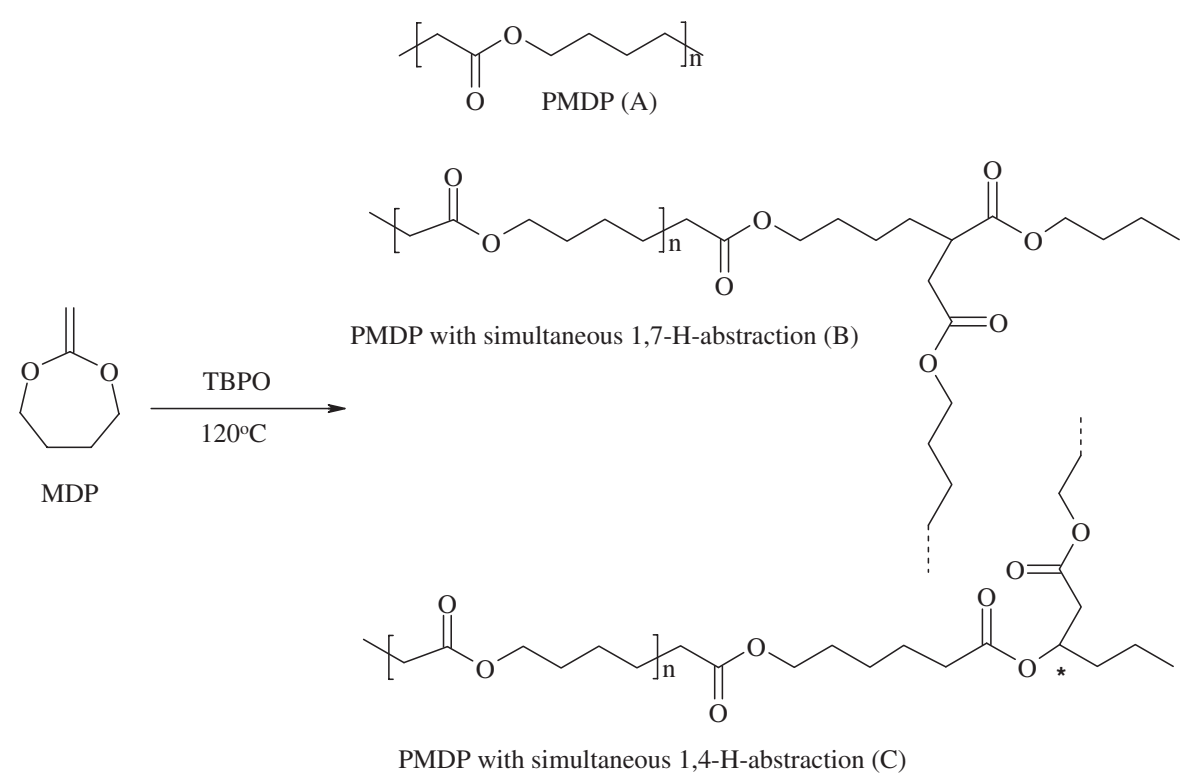

Scheme 2. RROP of MDP — some of the possibilities during radical ring-opening polymerisation.

ation in polymer structure from PCL. The ROP of cyclic ketene acetals and hence the resulting structure of the polymer is dependent on many factors and the temperature is one of them. Gonsalves et al. have shown the presence of 1,4- and 1,7-H-abstraction reactions leading to the formation of branches (total branch density $20 \%$ ) during RROP of MDP at $50{ }^{\circ} \mathrm{C}$ using AIBN as initiator for $72 \mathrm{~h}$ (Scheme 2). ${ }^{1 \mathrm{j}}$

They have used theoretically calculated values of chemical shifts for assigning peak positions in ${ }^{13} \mathrm{C}$ NMR spectrum. In our work, the RROP of MDP at $120^{\circ} \mathrm{C}$ showed no peak at ppm 69.6 in ${ }^{13} \mathrm{C}$ NMR spectrum expected from the branch point carbon marked with $*$ in the Scheme 2 after 1,4-H-abstraction reaction. This gives first indication of absence of 1,4-H-abstraction reactions during RROP at high temperature. The origin of other extra peaks in ${ }^{1} \mathrm{H}$ and ${ }^{13} \mathrm{C}$ NMR spectra appears to be mainly from the 1,7-H abstraction reactions. This is reconfirmed using 2D NMR techniques. 2D HMQC NMR spectrum is used for peak assignments in ${ }^{13} \mathrm{C}$ NMR spectrum corresponding to that of the ${ }^{1} \mathrm{H}$ NMR spectrum. The extra peaks in ${ }^{13} \mathrm{C}$ NMR at ppm 13, 83, 19.26, 23.32, $28.75,40.95$ corresponds to the corresponding peaks in ${ }^{1} \mathrm{H}$ NMR at ppm 0.92, 1.35, 1.34, 2.6 and 2.8 and shows the correlation peaks A, B, C, D and E respectively in HMQC NMR spectrum (Figure 2). The distinct extra peaks at ppm 31.45 and 35.85 showed no clear correlations in HMQC NMR spectrum and may be overlapping with some other peaks.

$2 \mathrm{D}{ }^{1} \mathrm{H}-{ }^{13} \mathrm{C}$ HMBC NMR spectrum is used to prove the correct assignment of the extra peaks originating from 1,7-H-abstraction reaction during RROP (Figure 3). The peak at ppm 0.92 in ${ }^{1} \mathrm{H}$ NMR spectrum and the corresponding peak at ppm 13.83 (15)

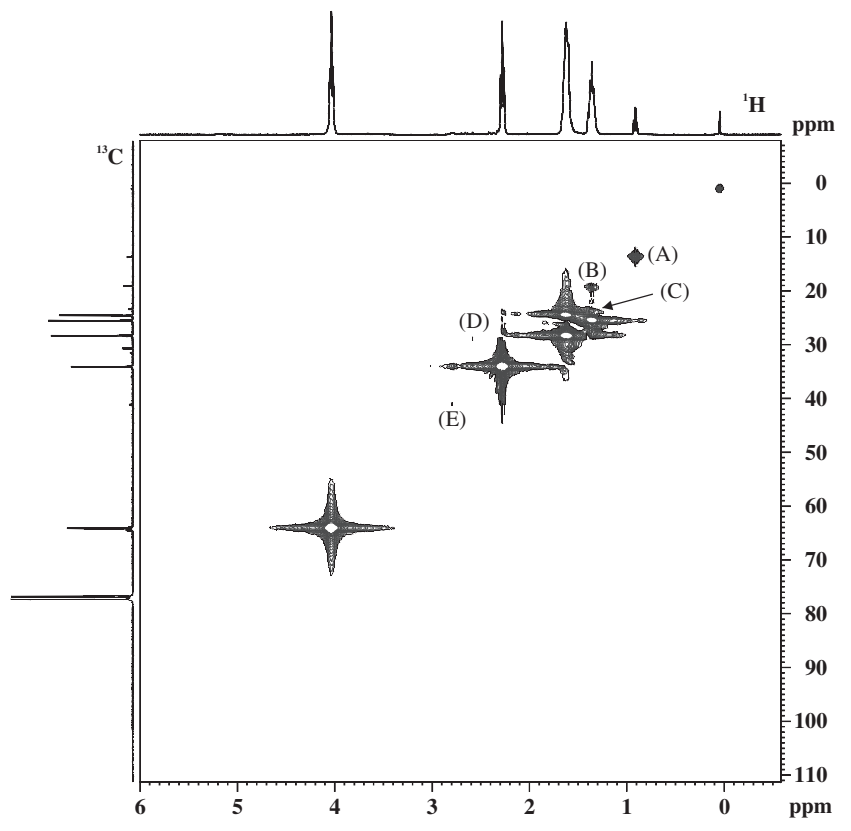

Figure 2. ${ }^{1} \mathrm{H}_{-}{ }^{13} \mathrm{C}$ HMQC NMR spectrum of PMDP.

in ${ }^{13} \mathrm{C}$ are assigned to the $-\mathrm{CH}_{3}$ group originating from 1,7-H-abstraction reaction. This peak shows correlations with peak at ppm 19.26 (14) (A) and ppm 30.92 (13) (B). Methyl proton (15) is expected to show two clear ( 2 bond with 14 and 3 bond with 13) correlations. The peak at ppm 19.26 in ${ }^{13} \mathrm{C}$ NMR spectrum which is assigned to the carbon 14 besides showing correlation with methyl group $(15, \mathrm{~A})$ showed two other correlations $\mathrm{C}\left({ }^{1} \mathrm{H}\right.$ peak at ppm 4.1) and $\mathrm{D}\left({ }^{1} \mathrm{H}\right.$ peak at ppm 1.7). This peak is also expected to show 2-bond correlation with proton 13 and 3 bond correlation with the proton 2 if our assignment is correct. This also gives a hint that the proton peak 


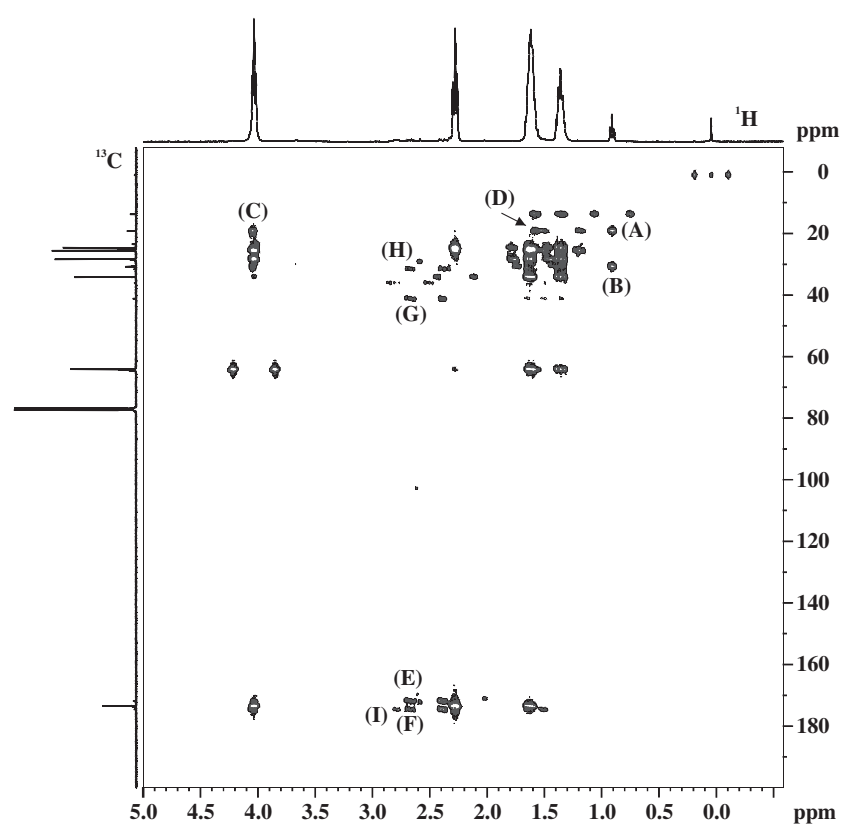

Figure 3. ${ }^{1} \mathrm{H}_{-}{ }^{13} \mathrm{C}$ HMBC NMR spectrum of PMDP.

of 13 is in an overlap with that of the protons 3 and 5 at ppm 1.7. The protons 11 are attached to an asymmetric carbon 9 and therefore are expected to show splitting in the ${ }^{1} \mathrm{H}$ NMR spectrum. The peaks between ppm 2.2-2.6 in ${ }^{1} \mathrm{H}$ NMR spectrum showed two correlation in the carbonyl carbon region with peaks at ppm $171.68(\mathrm{E})$ and $174.66(\mathrm{~F})$ and also correlation with the branched carbon $9(\mathrm{G})$ and the carbon $8(\mathrm{H})$. Also, the branched carbon 9 shows only one very clear correlation with carbonyl carbon at ppm 174.66 (I) and helps in the correct assignment of this carbonyl carbon peak to 12 . The careful examination of ${ }^{13} \mathrm{C}$ NMR spectrum showed no peak in the region ppm 100-110 and hence shows the occurrence of $100 \%$ ring-opening polymerization. The integration of peak areas in the ${ }^{1} \mathrm{H}$ NMR spectrum showed the presence of about $9 \%$ branched structures in the resulting polymer.
Due to the reduced branches PMDP chains in this study also showed crystallinity as compared to the other all previous studies showing only the formation of completely amorphous PMDP on radical-ringopening polymerization of MDP with glass transition temperature of about $-57^{\circ} \mathrm{C} .1 \mathrm{j}, 7$ The commercial PCL (Aldrich) shows glass transition temperature $\left(T_{\mathrm{g}}\right)$ around $-63^{\circ} \mathrm{C}$ and melting temperature $58^{\circ} \mathrm{C}$. Our PMDP $\left(M_{\mathrm{w}}=30,000\right)$ which was expected to have the basic structure like PCL showed $T_{\mathrm{g}}$ of $-61^{\circ} \mathrm{C}$ and two melting peak around $25^{\circ} \mathrm{C}$ and $36^{\circ} \mathrm{C}$ respectively (Figure 4). The branching in the polymer structure causes higher concentration of the end-groups thereby leading to the increased dislocations in the lamellar thickening process, a known effect, and hence the imperfect crystals. ${ }^{8}$ First time we are showing here a polyester structure very close to the PCL structure by RROP of MDP.

The representative ${ }^{1} \mathrm{H}$ NMR of copolymers is shown in Figure 5 (entry 4 Table I). The characteristic signals of both MMA and MDP were seen in the copolymers. The $-\mathrm{CH}_{2} \mathrm{C}(\mathrm{O}) \mathrm{OCH}_{2}-$ protons of $\mathrm{MDP}$ were seen as a broad peak between ppm 3.8-4.1. Methoxy (-OCH$\left.\underline{H}_{3}-\right)$ protons from MMA unit were observed as splitted peak centered on ppm 3.7. Other aliphatic protons of MDP $\left(-\underline{\mathrm{CH}}_{2} \mathrm{C}(\mathrm{O}) \mathrm{OCH}_{2} \mathrm{C}_{2} \mathrm{C}_{2}-\right.$ $\left.\mathrm{C}_{2}{ }^{-}\right)$and MMA $\left(-\underline{\mathrm{C}}_{2} \mathrm{C}\left(\mathrm{C}_{3}\right)\left(\mathrm{OCH}_{3}\right)-\right)$ were seen as overlapping signals between ppm 0.7-2.8. These peaks showed the presence of different configurational and conformational sequencing of the two comonomeric units (MDP and MMA) onto the polymer backbone.

The copolymer composition (Table I) was determined by using the peak intensities at ppm 3.8-4.1 $\mathrm{I}_{\mathrm{MDP}}\left(-\mathrm{CH}_{2} \mathrm{C}(\mathrm{O}) \mathrm{OCH}_{2}-\right.$ of MDP) and ppm 3.5-3.8 $\mathrm{I}_{\text {MMA }}\left(-\mathrm{OCH}_{3}\right)$ in ${ }^{1} \mathrm{H}$ NMR. The molar ratio of MMA: MDP in the copolymer was always found to be high as compared to that in the feed (Table I) but different

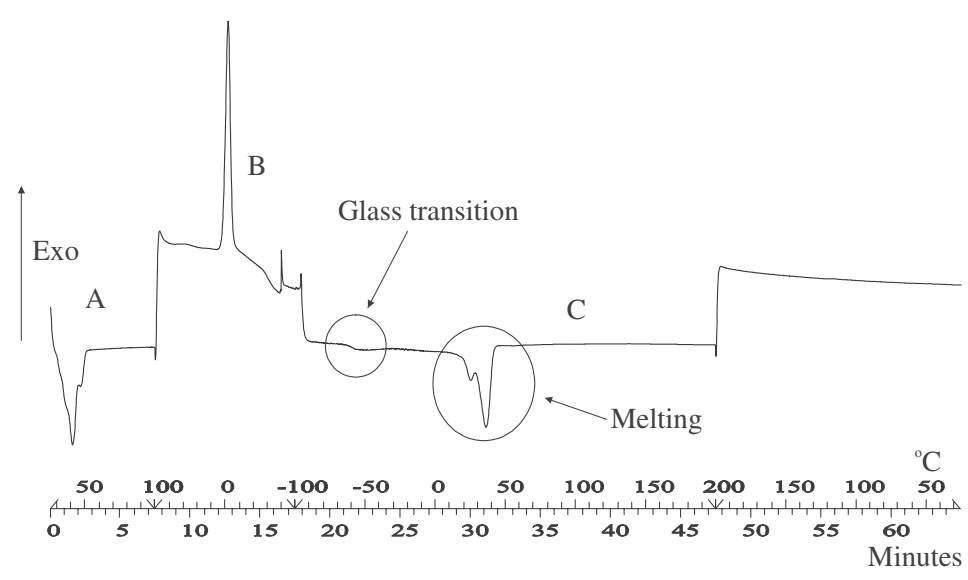

Figure 4. DSC curves of PMDP A) first heating cycle $\left(25-100^{\circ} \mathrm{C} ; 10 \mathrm{~K} / \mathrm{min}\right)$; B) cooling cycle $\left(100--100^{\circ} \mathrm{C} ; 10 \mathrm{~K} / \mathrm{min}\right)$; $\left.\mathrm{C}\right) \mathrm{second}$ heating cycle $\left(-100-200^{\circ} \mathrm{C} ; 10 \mathrm{~K} / \mathrm{min}\right)$. 


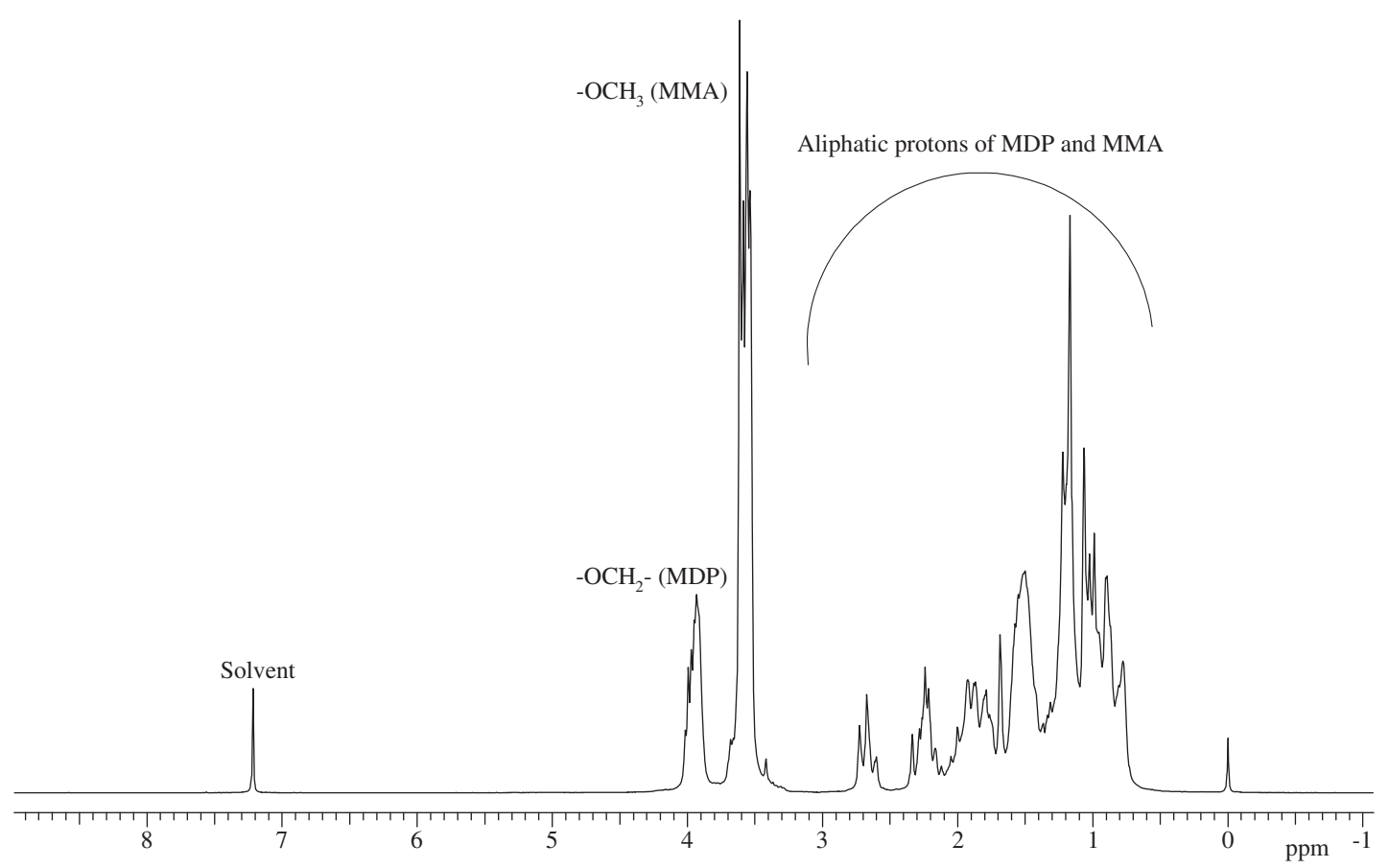

Figure 5. ${ }^{1} \mathrm{H}$ NMR spectrum of poly(MMA-co-ester) (run 4, Table I).

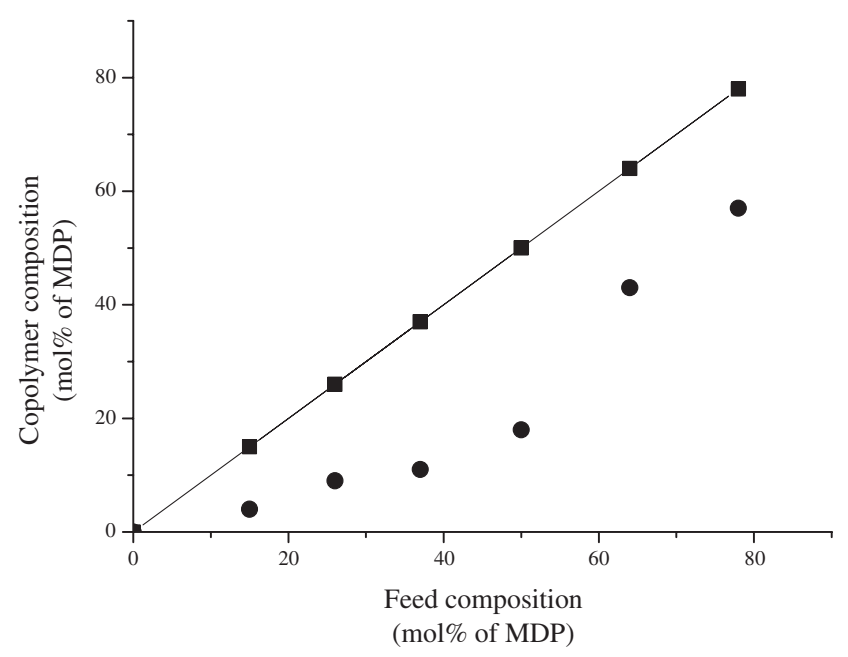

Figure 6. Plot of the feed composition (mol \% of MDP) vs. copolymer composition ( $\bullet$ actual values obtained; $\bullet$ ideal values).

copolymers could be made having increasing amount of MDP units just by changing the molar ratio of the two comonomers in the initial feed (Figure 6).

The molecular weight $\left(M_{\mathrm{n}}\right)$ of the obtained copolymers and the \% yield of the reaction decreased with increasing amount of the MDP units in the polymer chain under similar reaction conditions. But, in general very high molecular weight polymers ranging between $M_{\mathrm{n}}=50,000-190,000$ could be made (Table I). Reactivity ratios for MDP and MMA are determined using Kelen-Tüdos method ${ }^{9}$ and was determined to be $r_{\mathrm{MMA}}=3.5$ and $\mathrm{r}_{\mathrm{MDP}}=0.04$ (Figure 7). For reactivity ratio determinations the reactions were stopped at low conversions (15-20\%).

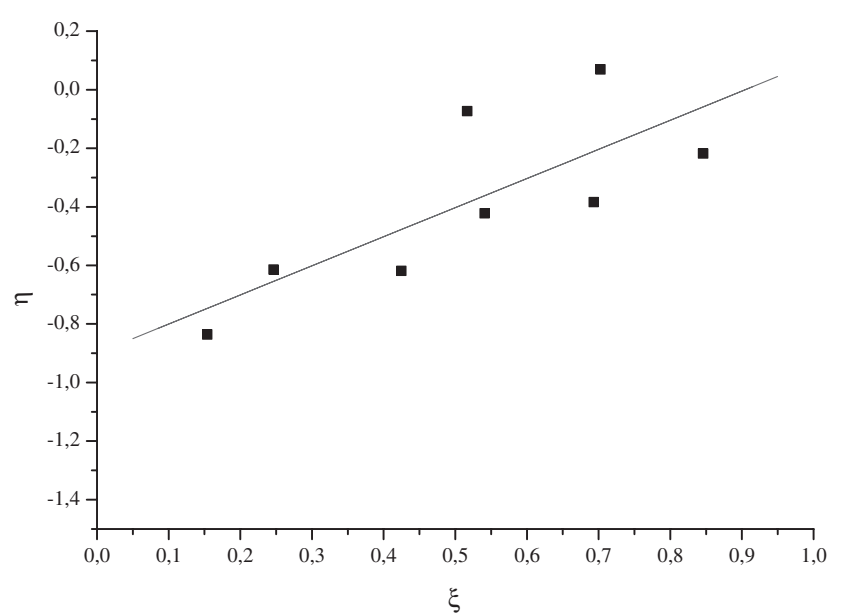

Figure 7. Kelen-Tüdos plot for the determination of reactivity ratios.

The reactivity parameters give an hint about the copolymer microstructure as long sequences of MMA separated by isolated or very small MDP sequences and shows the preference of both types of growing radicals (MMA and MDP) for the monomer MMA. The reactivity ratio data available in the literature for MDP during its copolymerisation with vinyl monomers also showed very high reactivity of the vinyl monomers as compared to the cyclic ketene acetals for example Bailey et al. showed rMDP $=0.021$; $\mathrm{r}_{\mathrm{St}}=22.6 .^{4 \mathrm{a}}$ On contrary to it, Davis et al. have reported a complete absence of copolymerisation and their experimental data indicated the homopolymerisation of styrene, with the MDO merely acting as a 
diluent. ${ }^{5}$ Davis et al. have reported copolymerisation parameters for copolymerisation of MDP with MMA at $40^{\circ} \mathrm{C}$ as $\mathrm{r}_{\mathrm{MDP}}=0.057$ and $\mathrm{r}_{\mathrm{MMA}}=34.12$ thereby showing the low tendency of cyclic ketene acetals to copolymerise with vinyl monomers. ${ }^{4 \mathrm{c}}$ The change in the reaction conditions like temperature or the comonomer structure could lead to an increased tendency for copolymerisation.

Further careful examination of the ${ }^{1} \mathrm{H}$ NMR spectrum helped in analysing the microstructure of the copolymers. The methoxy proton of homo poly (methyl methacrylate) is observed as a singlet at around ppm 3.5. In the copolymers the methoxy proton of MMA unit showed splitting which is assigned to the compositional sequencing (Scheme 3, Figure 8) in the copolymers and also therefore supports the random distribution of two monomeric units onto the polymer backbone. With increase in the amount of MDP in the copolymers the peak D in Figure 7 increased and the peak A decreased. The peak A by comparison with homo PMMA is assigned to the triad MMM (MMA-MMA-MMA) and other prominent three peaks should be from the triads $\mathrm{MMM}_{\mathrm{d}}, \mathrm{M}_{\mathrm{d}} \mathrm{MM}$ and $\mathrm{M}_{\mathrm{d}} \mathrm{MM}_{\mathrm{d}}$. This shows with increase in the amount of MDP in the copolymers the triads having MDP increases showing more randomisation of the copolymer structure.
Also, copolymerisation reaction was followed at different intervals of time and change in microstructure of the copolymers is studied with time. For a sample with initial feed molar ratio of MDP:MMA
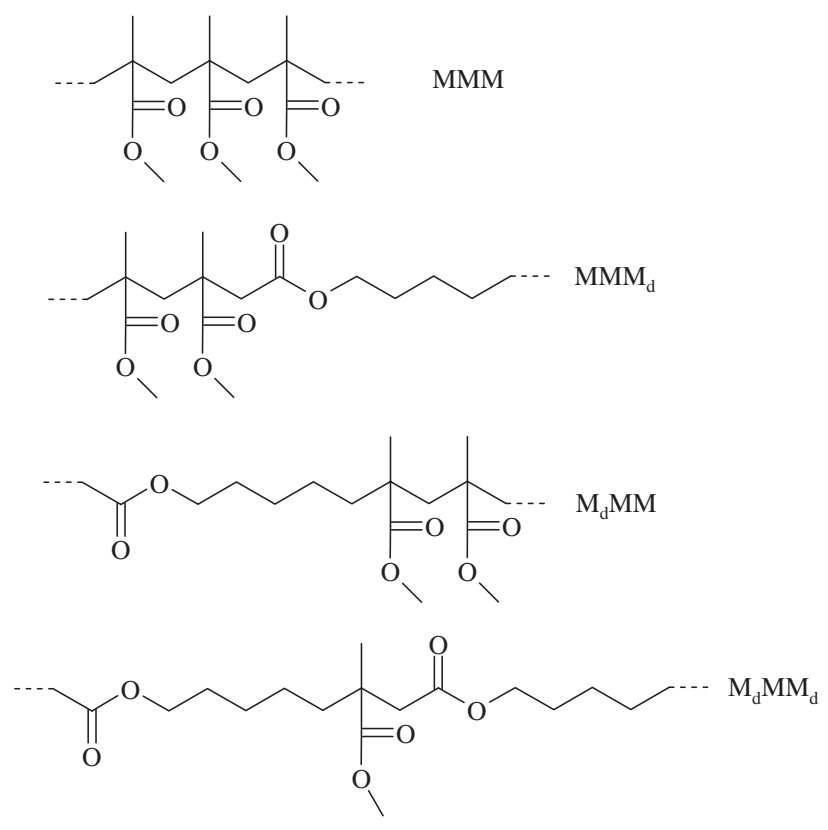

Scheme 3. Different compositional triads $\left(M=M M A ; M_{d}=\right.$ MDP).

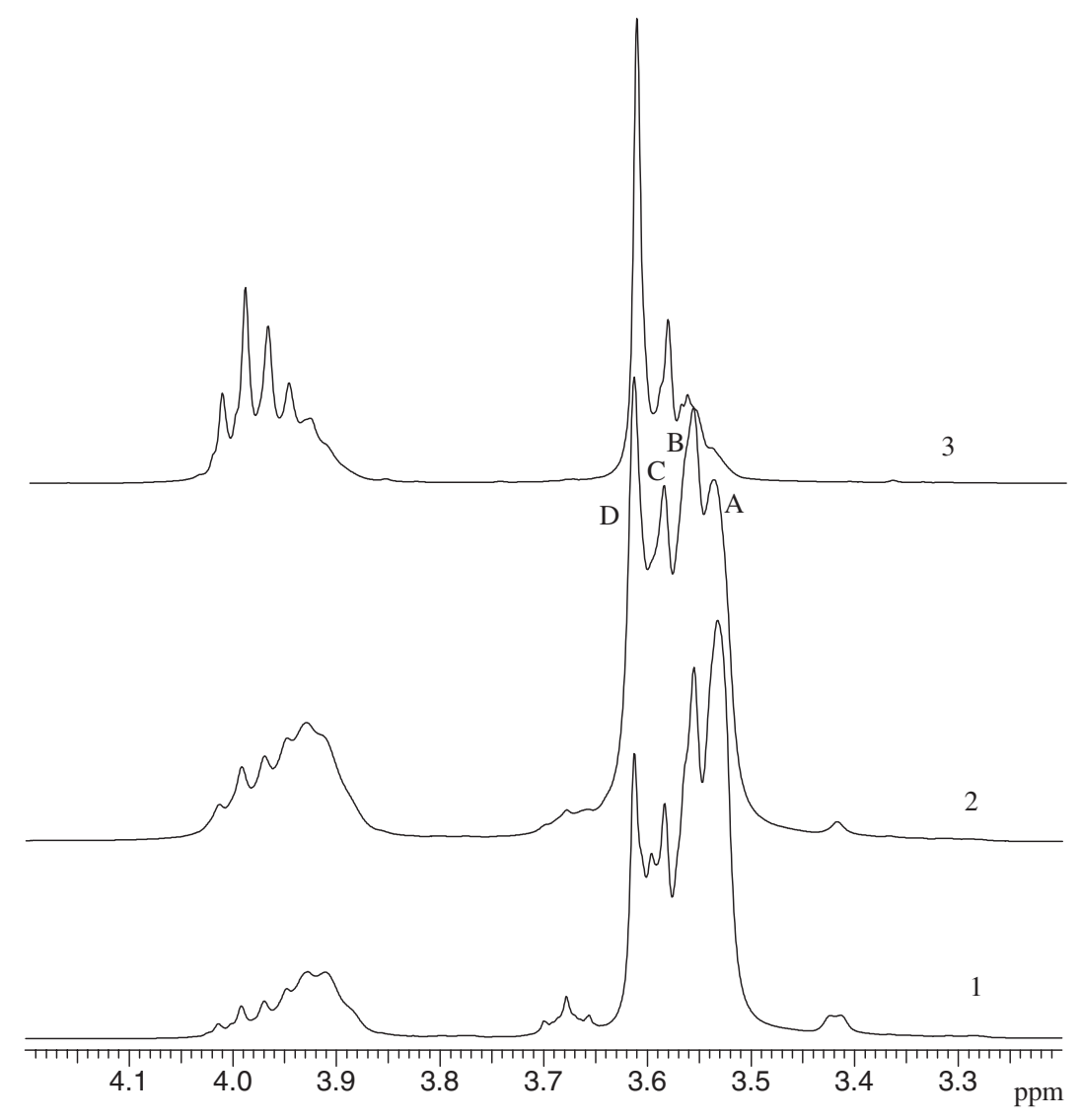

Figure 8. A part of the ${ }^{1} \mathrm{H}$ NMR spectra (ppm 3.2-4.2) 1) run 2 Table I; 2) run 4 Table I; 3) run 6 Table I. 
Table II. Copolymerisation of MMA and MDP using $1 \mathrm{wt} \%$ TBPO initiator $\left(\mathrm{Temp} .=120^{\circ} \mathrm{C}\right)$ for a feed composition MMA:MDP 1:1 (molar ratio) for different intervals of time

\begin{tabular}{|c|c|c|c|c|c|c|c|c|}
\hline \multirow[t]{3}{*}{ S.No. } & \multirow{3}{*}{$\begin{array}{c}\text { Time of } \\
\text { polymerisation } \\
(\min )\end{array}$} & \multirow[t]{3}{*}{$\begin{array}{l}\text { Yield } \\
(\%)\end{array}$} & \multirow{2}{*}{\multicolumn{2}{|c|}{$\begin{array}{l}\text { Copolymer } \\
\text { composition } \\
\text { (Molar ratio) }\end{array}$}} & \multicolumn{2}{|c|}{$\begin{array}{c}\text { Copolymer } \\
\text { composition }(\mathrm{g})\end{array}$} & \multirow[t]{3}{*}{$M_{\mathrm{n}} \times 10^{-4}$} & \multirow[t]{3}{*}{$M_{\mathrm{w}} / M_{\mathrm{n}}$} \\
\hline & & & & & \multirow[t]{2}{*}{ MMA } & \multirow[t]{2}{*}{ MDP } & & \\
\hline & & & MMA & MDP & & & & \\
\hline 1 & 10 & 8 & 86 & 14 & 14.3 & 2.7 & 11.0 & 1.7 \\
\hline 2 & 30 & 19 & 80 & 20 & 33.5 & 7.5 & 8.3 & 2.1 \\
\hline 3 & 60 & 57 & 74 & 26 & 87 & 35 & 10.0 & 2.2 \\
\hline 4 & 120 & 61 & 70 & 30 & 88 & 43 & 12.2 & 2.0 \\
\hline
\end{tabular}

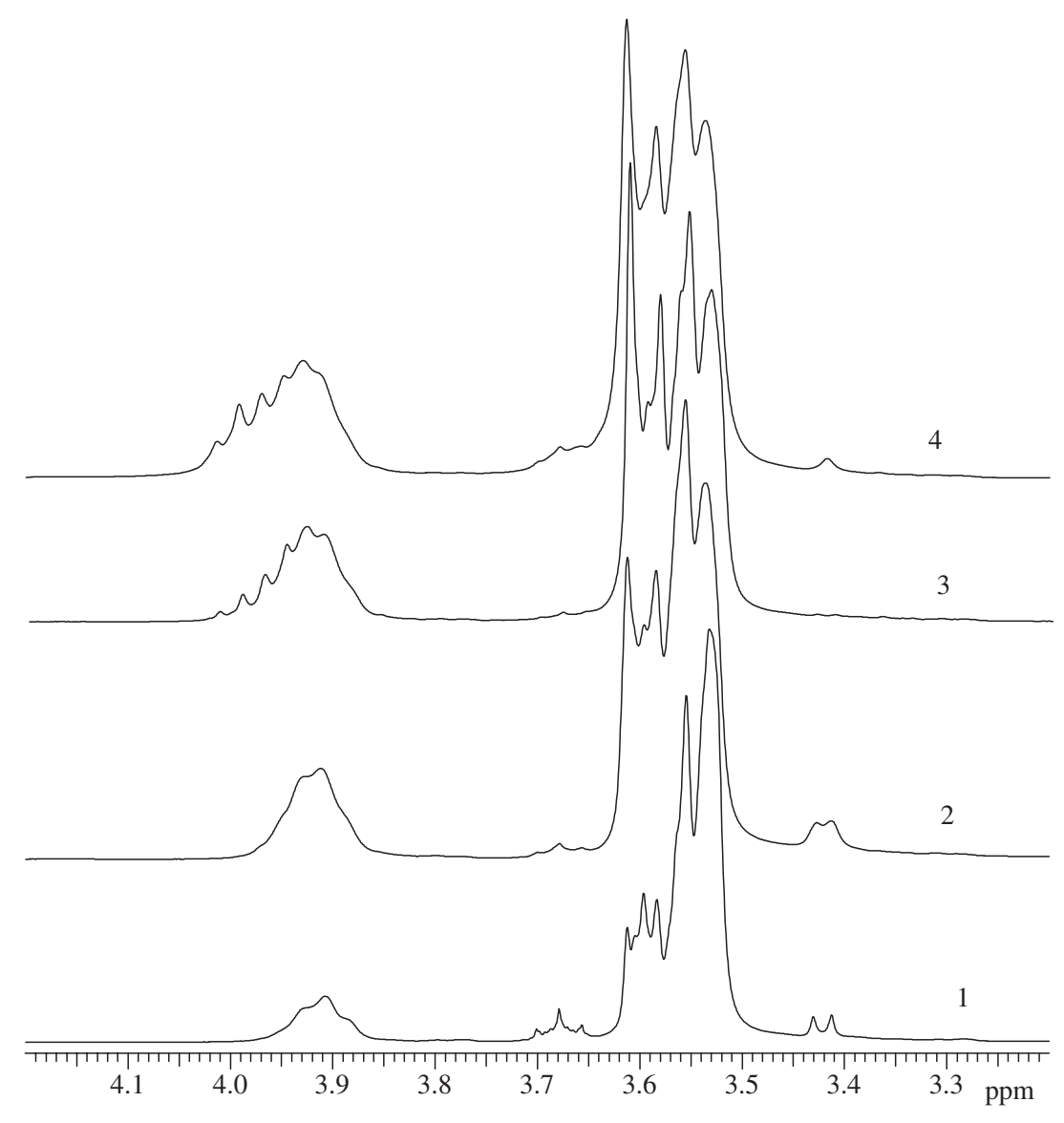

Figure 9. A part of the ${ }^{1} \mathrm{H}$ NMR spectra (ppm 3.2-4.2) for poly (MMA-co-ester) made from MMA:MDP 50:50 (molar ratio) feed composition for different intervals of time, 1) run 1 Table III; 2) run 2 Table III; 3) run 3 Table III; 4) run 4 Table III.

$1: 1$, copolymer composition was determined at different time intervals using ${ }^{1} \mathrm{H}$ NMR technique and is given in Table II.

Also, it is possible to calculate theoretically the amount of MMA and MDP reacted at different intervals of time depending on the copolymer composition and the corresponding yield of the copolymer obtained. It can be seen from the calculated data (Table II) that rate of consumption of MMA was more at the start. This also gives a hint that at the start there were more MMM type of sequences followed by the more randomisation and more $\mathrm{MMM}_{\mathrm{d}}, \mathrm{M}_{\mathrm{d}} \mathrm{MM}$ and $\mathrm{M}_{\mathrm{d}} \mathrm{MMd}$ triads. This can be seen from splitting pattern of the methoxy proton of MMA in different copolymers at different reaction times also (Figure 9). After about $1 \mathrm{~h}$ of the polymerisation time the increase in the yield is mainly due to the incorporation of MDP in the copolymers also showing the increased amount of $\mathrm{M}_{\mathrm{d}} \mathrm{M}_{\mathrm{d}} \mathrm{M}_{\mathrm{d}}$ type triads. High molecular weight polymer was formed at the start of the reaction and with time only the yield increased without significant increase in the molecular weight (Table II).

Further careful examination of 2D HMBC NMR spectrum could also help in proving a chemical link between the two monomeric units, i.e., MMA and $\mathrm{MDP}$ in the copolymers. The linking $-\underline{\mathrm{C}}_{2} \mathrm{C}(\mathrm{O}) \mathrm{O}-$ 
$\mathrm{CH}_{2}$ - unit (1) of MDP (Figure 10) in the diad MMAMDP is expected to show splitted peaks as it is attached to an asymmetric carbon and is also expected to show upfield shift as compared to $-\mathrm{CH}_{2} \mathrm{C}(\mathrm{O}) \mathrm{OCH}_{2}-$ proton of MDP-MDP diad. The upfield peaks between ppm 2.3-2.8 showed correlations with both carbonyl carbons of MDP (cross peaks A and C) and MMA (cross peaks $\mathrm{B}$ and $\mathrm{D}$ ) units. This could originate only from the linking $-\mathrm{CH}_{2} \mathrm{C}(\mathrm{O}) \mathrm{OCH}_{2}$ - unit.

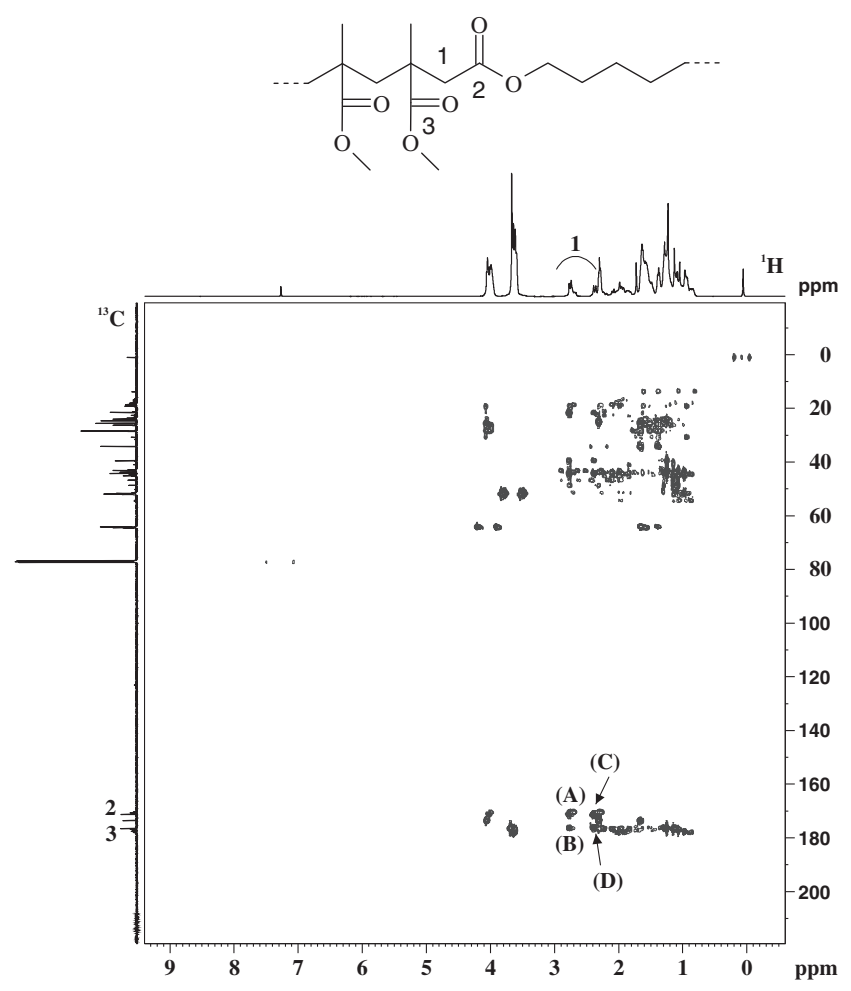

Figure 10. ${ }^{1} \mathrm{H}-{ }^{13} \mathrm{C} \mathrm{HMBC}$ NMR spectrum of poly (MMA-coester) (run 4 Table I).
Effect of the incorporation of MDP ester units onto the PMMA hydrocarbon chain is also investigated on the thermal stability and glass transition temperature of PMMA. The thermal stability is compared using the parameters, $T_{\mathrm{i}}$ (extrapolated initial decomposition temperature) and $T_{\max }$ (the temperature at which the maximum weight loss occurs) (Table III). The degradation of PMMA prepared by the radical polymerisation generally takes place in two-three steps. ${ }^{10}$ In this work, PMMA prepared under similar conditions by radical initiator showed three step degradations. The steps at lower temperatures $\left(T_{\max } 180^{\circ} \mathrm{C}\right.$ and $\left.295^{\circ} \mathrm{C}\right)$ are assigned to the weak linkages and the chain end initiated thermal degradations. The step at $T_{\max }$ about $371^{\circ} \mathrm{C}$ is due to the random chain scission. Homo PMDP showed one-step degradation with $T_{\mathrm{i}}=382^{\circ} \mathrm{C}$ and $T_{\max }=416^{\circ} \mathrm{C}$ (Figure 11).

Incorporation of MDP in PMMA backbone led again to one-step degradation as compared to the three

Table III. Thermal properties of poly (MMA-co-ester)s

\begin{tabular}{rrccccc}
\hline $\begin{array}{c}\text { Copolymer } \\
\text { composition } \\
\text { (Molar ratio) }\end{array}$ & $\begin{array}{c}T_{\mathrm{g}}{ }^{\circ} \mathrm{C} \\
\text { (Observed) }\end{array}$ & $\begin{array}{c}T_{\mathrm{g}} \\
\text { (Calculated) }\end{array}$ & $T_{\mathrm{m}}{ }^{\circ} \mathrm{C}$ & $T_{\mathrm{i}}{ }^{\circ} \mathrm{C}$ & $T_{\max }{ }^{\circ} \mathrm{C}$ \\
MDP & MMA & & & & & \\
\hline 10 & 90 & 78 & 80 & & 366 & 407 \\
16 & 84 & 61 & 60 & & 368 & 409 \\
22 & 78 & 31 & 42 & & 369 & 411 \\
30 & 70 & 20 & 22 & & 368 & 410 \\
44 & 56 & -9 & -7 & $48^{\mathrm{a}}$ & 373 & 406 \\
57 & 43 & -23 & -23 & $41^{\mathrm{a}}$ & 383 & 413 \\
100 & 0 & -61 & & $25 / 36$ & 382 & 416 \\
0 & 100 & 120 & & & $159^{\mathrm{b}}$ & 180 \\
\hline
\end{tabular}

${ }^{\mathrm{a} S e e n}$ only in the first heating cycle. ${ }^{\mathrm{b}}$ Showed three step degradation.

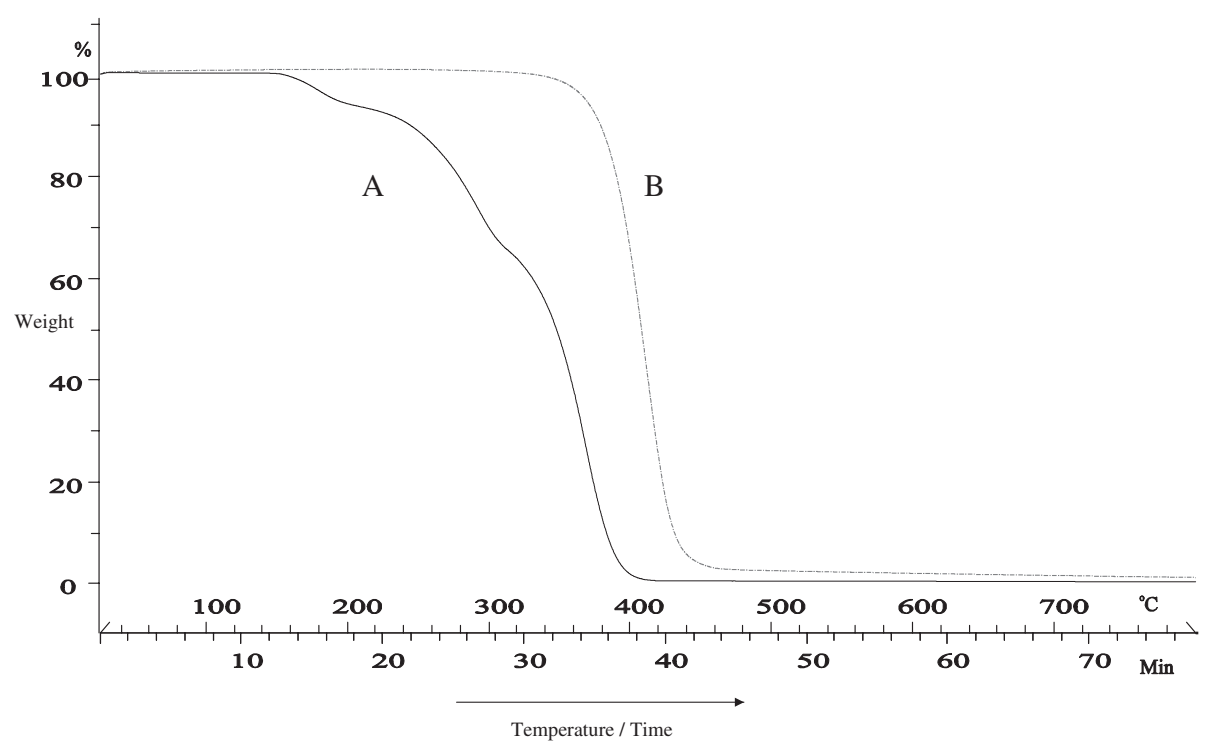

Figure 11. TGA curves A) PMMA; B) PMDP. 

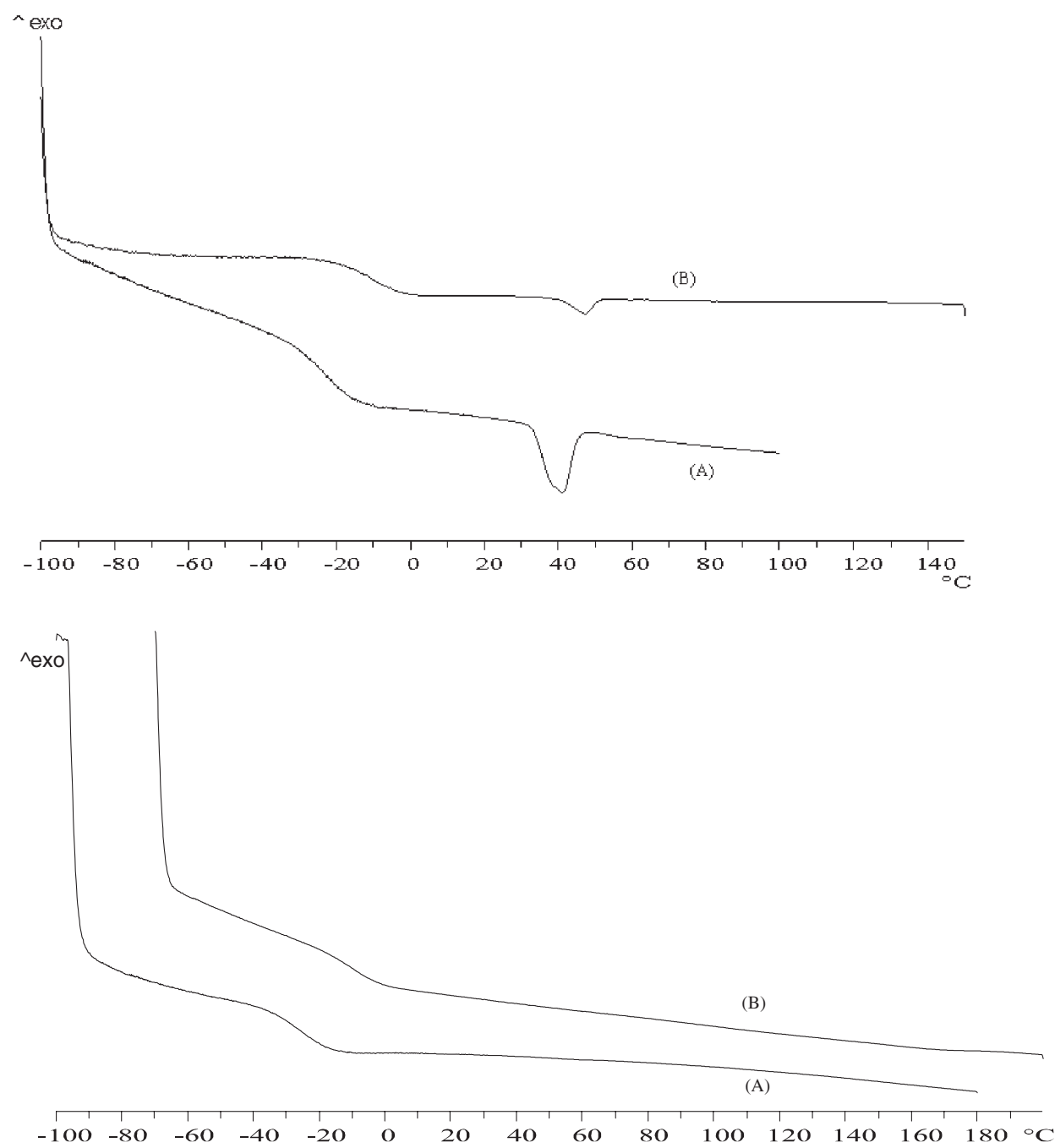

Figure 12. DSC traces; top-first heating cycle A) run 6; B) run 5: bottom-second heating cycle A) run 6; B) run 5 .

step degradation of PMMA with the increased $T_{\mathrm{i}}$ and $T_{\max }$ values (Table III). There are specific efforts in the literature by us and the others to improve thermal stability of PMMA by incorporating $N$-substituted maleimides, bismaleimides, itaconimides, and cardanyl acrylate etc. ${ }^{11}$ In the present studies we observed that incorporation of very low $\mathrm{mol} \%(10 \mathrm{~mol} \%)$ of the MDP units onto the PMMA backbone prevented the thermal degradation of PMMA at lower temperatures (the peaks at $T_{\max } 180^{\circ} \mathrm{C}$ and $295^{\circ} \mathrm{C}$ ) completely disappeared) and random chain was the only degradation path observed at higher temperature. Further increase in the amount of MDP in the copolymers led to a marginal increase in the $T_{\mathrm{i}}$ and $T_{\max }$ values (Table III). Single glass transition temperature was observed for the copolymers (poly(MMA-co-ester)s. There is a decrease in the glass transition temperature on increasing the amount of MDP onto the PMMA backbone. A good correlation between the observed glass transition temperatures and the calculated ones using Fox equation was seen. The copolymers having higher amounts of MDP (runs 5 and 6, Table I) were crystalline and showed meting peaks in the first heating cycle also (Figure 12). For DSC measurements the samples were heated in the first heating cycle from $-100^{\circ} \mathrm{C}$ till $150^{\circ} \mathrm{C}$ at a heating rate of $10 \mathrm{~K} / \mathrm{min}$. The samples were cooled again to $-100{ }^{\circ} \mathrm{C}$ with a cooling rate of $10 \mathrm{~K} / \mathrm{min}$ and again heated in the second heating cycle till $200^{\circ} \mathrm{C}$. The glass transition temperatures are noted in the Table III from the second heating cycle. We have shown before that with increased amount of MDP in the copolymers the triads of the types $M_{d} M_{d} M_{d}$ increased and therefore is responsible for showing melting behaviour in the some of the copolymers like PCL.

Since the incorporation of ester linkages are expected to introduce degradability and was one of the aims of this work, the studies on hydrolytic degradation of the MDP-MMA copolymer samples were carried out in $\mathrm{KOH}(5 \mathrm{wt} \%$ in $\mathrm{MeOH})$. After 3-4h of hydrolysis, the homo PMDP was completely soluble in the hydrolysis medium. The degraded material was extract- 
ed with chloroform, dried over sodium sulphate and after evaporation and drying the left over waxy/oily material is subjected to GPC analysis. The GPC showed no peak at high molecular weight region and showed complete degradation of PMDP into small units that could not be detected by our GPC system. PMMA was also hydrolysed for the comparison and the GPC traces before and after hydrolysis are shown in the Figure 13. PMMA under similar and prolonged hydrolysis time of $8 \mathrm{~h}$ was not degradable. The copolymer samples having 16 and $30 \mathrm{~mol} \%$ of ester units are tried for hydrolytic degradation and showed dissolution in hydrolytic medium in about 8-9 h time and the disappearance of the high molecular weight peak in GPC hereby showing their hydrolytic degradability tendency (Figure 13).
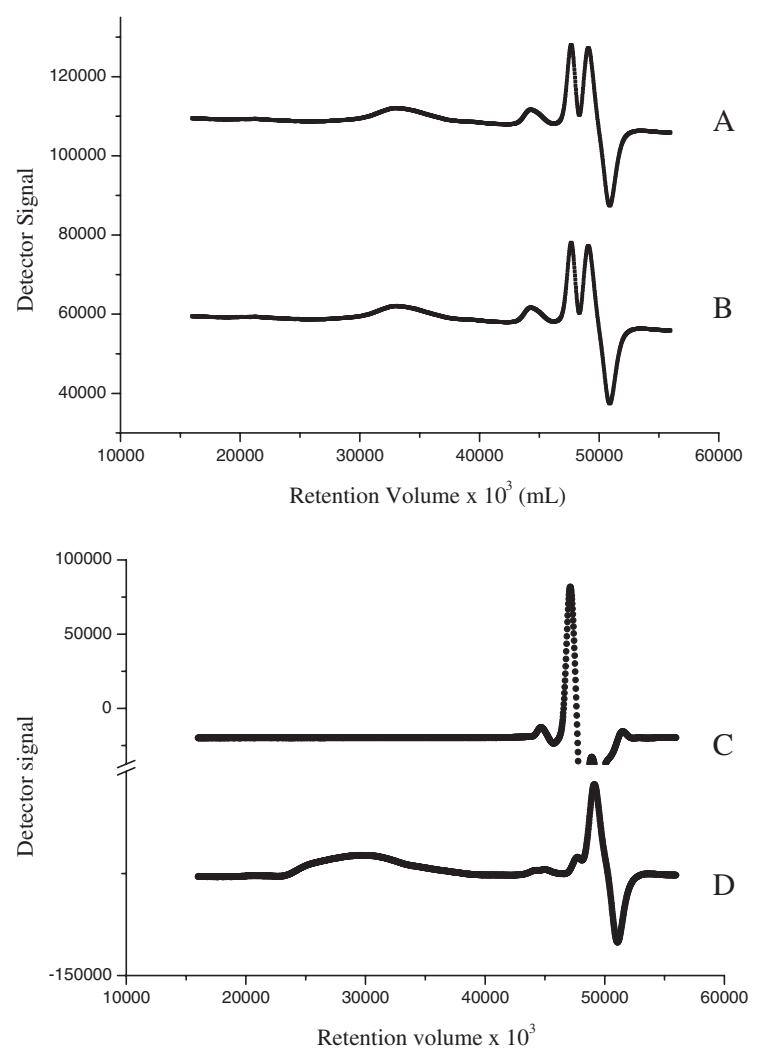

Figure 13. GPC traces of A) PMMA before hydrolytic degradation; B) PMMA after degradation; C) poly (MMA-co-ester) run 4 Table I after hydrolysis; D) poly (MMA-co-ester) run 4 Table I before hydrolysis.
The microstructure of the copolymers with random blocky structure with capability of crystallisation depending upon the amount of ester linkages, their high molecular weights and our observation of elastic behaviour (not reported with this work) on introducing very low mol \% of ester linkages led us to carry out some preliminary studies for showing utility of these materials poly(MMA-co-ester)s for heat-shrinkable property. The microcrystallites could act as physical cross-links. A small piece from the film made by solution casting, for example of run 3 Table $\mathrm{I}$, is stretched in warm water at $70^{\circ} \mathrm{C}$ and this stretched state is immediately frozen by putting it in ice cold water. After reheating the stretched sample in warm water it shrinks and takes its own original dimensions and shape (Figure 14). Further detailed studies and the effect of amount of ester linkages, molecular weight etc. on this behaviour will be studied and communicated in future publications.

\section{CONCLUSION}

Crystalline behaviour of aliphatic polyester PMDP prepared using radical-ring-opening-polymerisation of MDP is reported for the first time. Complete microstructural characterisation of homo- and poly(MMAco-ester)s is carried out using 1D and 2D NMR techniques and the copolymer structure is found to be random with comparatively long blocks of MMA units. Incorporation of very low amounts of MDP units onto the PMMA backbone is shown to provide PMMA with increased thermal stability besides introducing hydrolytic degradability capability. The new materials can be provided with a range of glass transition temperatures and from amorphous to crystalline depending on the starting feed ratios. The resulting copolymers also showed promising behaviour as heat shrinkable degradable materials with shape memory property, the details of which will be communicated in our next paper.

Acknowledgment. The author would like to thank Deutsche Forschungsgemeinschaft (DFG), Germany for the financial support and Prof. Andreas Greiner for useful discussions.
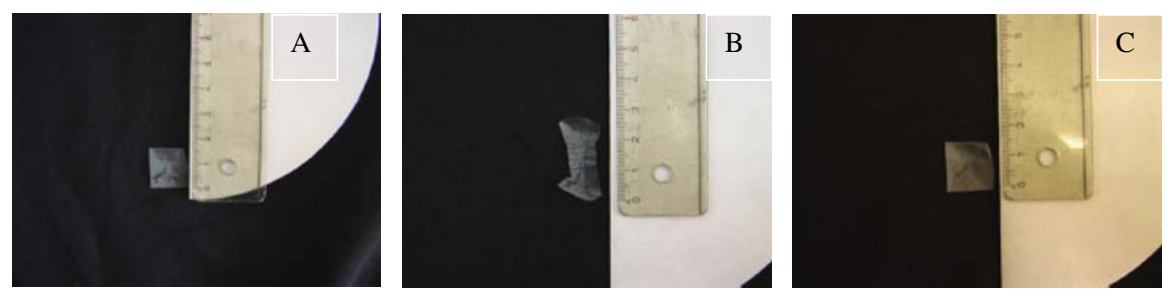

Figure 14. Heat-shrinkable property A) original sample B) stretched sample C) sample returned to the original form. 


\section{REFERENCES}

1. a) W. J. Bailey, S. R. Wu, and Z. Ni, Macromol. Chem., 183, 1913 (1982).

b) C. Y. Pan, Y. Wang, and W. J. Bailey, J. Polym. Sci., Part A: Polym. Chem., 26, 2737 (1988).

c) W. J. Bailey, Z. Ni, and S. R. Wu, Macromolecules, 15, 711 (1982).

d) J. Y. Yuan and C. Y. Pan, Eur. Polym. J., 38, 1565 (2002).

e) J. Y. Yuan and C. Y. Pan, Chin. J. Polym. Sci., 20, 171 (2002).

f) J. Y. Yuan and C. Y. Pan, Chin. J. Polym. Sci., 20, 9 (2001).

g) W. J. Bailey and T. Endo, J. Polym. Sci., Polym. Chem., 64, 17 (1978).

h) B. Wu, R. Lenz, and W. J. Bailey, J. Environ. Polym. Degrad., 6, 23 (1998).

i) M. H. Acar, Y. Nambu, K. Yamamoto, and T. Endo, J. Polym. Sci., Polym. Chem., 27, 4441 (1989).

j) S. Jin and K. E. Gonsalves, Macromolecules, 30, 3104 (1997).

k) T. Endo, M. Okawara, W. J. Bailey, K. Azuma, K. Nate, and H. Yokono, J. Polym. Sci., Polym. Lett. Ed., 21, 373 (1983).

1) T. Endo, N. Yako, K. Azuma, and K. Nate, Macromol. Chem., 186, 1543 (1985).

m) Y. Wie, E. J. Connors, X. Jia, and C. Wang, J. Polym. Sci., Polym. Lett. Ed., 36, 761 (1998).

2. a) H. Wickel, S. Agarwal, and A. Greiner, Macromolecules, 36, 2397 (2003).

b) H. Wickel and S. Agarwal, Macromolecules, 36, 6152 (2003).
3. a) S. Agarwal, J. Polym. Res., 13, 403 (2006).

b) S. Agarwal and M. Bognitzki, Polym. Prepr. (Am. Chem. Soc., Div. Polym. Chem.), 47, 528 (2006).

4. a) W. J. Bailey, Z. Ni, and S. R. Wu, J. Polym. Sci., Polym. Chem. Ed., 20, 3021 (1982).

b) S. Jin and K. E. Gonsalves, Macromolecules, 31, 1010 (1998).

c) G. E. Roberts, M. L. Coote, J. P. A. Heuts, L. M. Morris, and T. P. Davis, Macromolecules, 32, 1332 (1999).

5. L. M. Morris, T. P. Davis, and R. P. Chaplin, Polymer, 42, 495 (2001).

6. a) S. Agarwal, N. Naumann, and X. Xie, Macromolecules, 35, 7713 (2002).

b) S. Agarwal and X. Xie, Macromolecules, 36, 3545 (2003).

7. a) S. Borkar, A. Sen, and J. R. Shallenberger, J. Polym. Sci., Part A: Polym. Chem., 44, 1225 (2006).

b) L. F. Sun, R. X. Zhou, and Z. L. Liu, J. Polym. Sci., Part A: Polym. Chem., 41, 2898 (2003).

8. Y. P. Huang, X. Xu, X. L. Luo, and D. Z. Ma, Chin. J. Polym. Sci., 20, 45, (2002).

9. T. Kelen and F. Tüdos, J. Macromol. Sci., Part A: Pure Appl. Chem., 9, 1 (1975).

10. T. Kashiwagi, A. Inaba, J. E. Brown, K. Hafada, T. Kitayama, and E. Masuda, Macromolecules, 19, 2160 (1986).

11. a) L. Choudhary, D. S. Varma, I. K. Varma, and F. W. Wang, J. Therm. Anal. Calorim., 39, 633 (1993).

b) R. Bharel, V. Choudhary, and I. K. Varma, J. Appl. Polym. Sci., 54, 2857 (1994).

c) S. Agarwal, V. Chaudhary, and I. K. Varma, J. Appl. Polym. Sci., 46, 1707 (1992).

d) V. Anand, S. Agarwal, A. Greiner, and V. Choudhary, Polym. Int., 54, 823 (2005). 